\title{
Effect of Anticholinergic Drugs on Striatal Acetylcholine Release and Motor Activity in Freely Moving Rats Studied by Brain Microdialysis
}

\author{
Hiroshi WATANABE and Hiroko SHIMIZU \\ Department of Pharmacology, Research Institute for Wakan-Yaku. \\ Tovama Medical and Pharmaceutical University. Toyama 930-01, Japan
}

Accepted May 22, 1989

\begin{abstract}
We have studied effects of intraperitoneal administration of anticholinergic drugs on striatal acetylcholine release in association with motor activity in freely moving rats using brain microdialysis. A low dose of atropine $(2.5 \mathrm{mg} / \mathrm{kg})$ increased striatal acetylcholine release. A high dose of atropine $(5 \mathrm{mg} / \mathrm{kg})$ or scopolamine $(2.5,5$ and $10 \mathrm{mg} / \mathrm{kg}$ ) increased both striatal acetylcholine release and motor activity. while its quaternary ammonium compounds, atropine methylbromide ( 5 and $10 \mathrm{mg} / \mathrm{kg}$ ) and methscopolamine bromide (5 and $10 \mathrm{mg} / \mathrm{kg}$ ), increased striatal acetylcholine release without motor excitation. Scopolamine $(2.5 \mathrm{mg} / \mathrm{kg})$ produced no significant change in striatal acetylcholine content $4 \mathrm{hr}$ after the injection followed by perfusion. These results suggest that anticholinergic drugs cause an increase in striatal acetylcholine release which does not always result in the increase of motor activity.
\end{abstract}

Anticholinergic drugs facilitate stereotyped behavior and locomotor activity induced by dopamine receptor agonists $(1-3)$. Some anticholinergic drugs by themselves produce a behavior with stereotypy and motor excitation in animals $(4,5)$ and also turning behavior in mice with unilateral lesion of the nigro-striatal dopaminergic system $(3,6)$. Although these effects may be interpreted by the dopamine/acetylcholine balance model $(7,8)$, a comparison between the behavioral effects of anticholinergic drugs and brain acetylcholine release have not been studied in detail. A relationship between the decrease in brain acetylcholine content and increased locomotor activity following anticholinergic drugs was reported in mice (9). The correlation, however, between increase in acetylcholine release from the cerebral cortex and motor activity was not found in rats given anticholinergic compounds (10).

The in vivo brain dialysis technique in freely moving rats is very useful for comparing such effects (11). The aim of this study was to investigate the relationship between the increase in striatal acetylcholine release and motor activity following administration of anticholinergic drugs using this method.

\section{Materials and Methods}

Animals: Male Wistar rats $(280-350 \mathrm{~g}$. Shizuoka Laboratory Animal Center. Shizuoka) were housed under conditions of constant humidity, temperature and lighting (on 0700, off 1900) and used throughout the study. All experiments were conducted in the light hours.

Surgery: The rat was anesthetized with pentobarbital ( $50 \mathrm{mg} / \mathrm{kg}$, i.p.) and placed in a stereotaxic apparatus. A dialysis tube $(0.2$ $\mathrm{mm}$ outer diameter, acrylic copolymer with a 50,000 molecular weight cutoff: Asahi Medical Co.) was implanted transversely into the head of the caudate nucleus as reported by previous workers (12). The outer surface of the dialysis tube had been covered by Epoxy resin, except for two zones, $3.5 \mathrm{~mm}$ wide. separated by a central zone, $3.0 \mathrm{~mm}$ wide, also covered by the resin. The coordinates of implantation were A. $1.1 \mathrm{~mm}$ from the bregma and $V, 6.0$ from the surface of the parietal cortex, according to the brain atlas (13). Two 
days after the implantation, the rat was placed in a plastic cage $\left(30 \times 35 \times 18 \mathrm{~cm}^{3}\right)$ set on an automated activity meter and the inlet to the dialysis tube was connected to a constant-flow perfusion pump by polyethylene tubing with the interposition of a liquid swivel. Ringer solution containing 1 or $2 \mu \mathrm{M}$ of neostigmine was pumped into the dialysis tube at a rate of $2 \mu \mathrm{l} / \mathrm{min}$, and the solution emerging from the other end of the tube was collected every $15 \mathrm{~min}$ into a minitube. Five $\mu l$ of Ringer solution containing 10 $\mu \mathrm{M}$ of ethylhomocholine as an internal standard was added to the perfusate. At the end of the experiment the rat was perfused with $5 \%$ formalin-saline through the heart under pentobarbital anesthesia. Brain sections were cut and examined micro- and/or macroscopically for localization of the dialysis tube. Only samples with appropriate location of the tube in the striatum were included in the biochemical data.

Tissue content: Some of the rats injected with scopolamine were sacrificed by decapitation after a $5.5 \mathrm{hr}$-perfusion. The striatum around the dialysis tube was excised and frozen in liquid nitrogen. The tissue was weighed and homogenized in $1 \mathrm{ml}$ of $0.2 \mathrm{~N}$ perchloric acid containing ethylhomocholine (2 $\mathrm{nmol} / \mathrm{ml}$ ) and 3,4-dihydroxybenzylamine $(40 \mathrm{ng} / \mathrm{ml})$ as internal standards. The homogenized tissue was centrifuged at $10,000 \times \mathrm{g}$ for $10 \mathrm{~min}$.

Acetylcholine determination: To estimate acetylcholine, the collected solution or supernatant of tissue homogenate was directly injected into a high pressure liquid chromatography equipped with a precolumn (AC-ODS. Eicom), a separate column (Eicompac ACgel, Eicom) and an immobilized enzyme column (AC-Enzympac, Eicom) and an electrochemical detector operating at a flow rate of $1.0 \mathrm{ml} / \mathrm{min}$. The mobile phase consisted of $0.1 \mathrm{M}$ phosphate buffer solution ( $\mathrm{pH} 8.0$ ) containing $150 \mathrm{mg} / \mathrm{L}$ sodium 1-decanesulfonate (Tokyo Kasei) and $65 \mathrm{mg} / \mathrm{L}$ tetramethylammonium chloride (Nacalai Tesque). An amperometric controller equipped with a platina electrode (Eicom ECD-100) was used for electrochemical monitoring of the column eluates. The detector potential was maintained at $450 \mathrm{mV}$ versus an $\mathrm{Ag} / \mathrm{AgCl}$ reference electrode (14, 15). Apparent recovery of acetylcholine through the dialysis tube was $46.9 \pm 8.7 \%$ in vitro. The level of acetylcholine was not corrected by the recovery and expressed as pmol/15 min or percentages of the mean of three control samples taken immediately before injection of drugs.

Motor activity: Spontaneous motor activity was measured by setting the rat cage on an Animex (MK-110. Muromachi Kikai, Tokyo) and recording the counts for successive 15min periods immediately after beginning of perfusion in order to minimize the effects of arousal in a novel environment.

Drugs: Atropine sulfate (Nacalai Tesque, Kyoto), scopolamine hydrobromide (Nacalai). atropine methylbromide (Sigma Chemicals) and methscopolamine bromide (Sigma) were dissolved in sterile saline and injected into rats intraperitoneally. Neostigmine bromide (Nacalai) was dissolved in Ringer solution. Doses of drugs are expressed as the amount of salt.

Statistics: Data were analyzed by one way ANOVA with Duncan's multiple comparison test.

\section{Results}

Basal levels of acetylcholine release were stable over $5 \mathrm{hr}$ after the beginning of perfusion with Ringer solution containing 1 or 2 $\mu \mathrm{M}$ of neostigmine. The level of three control samples taken immediately before the drug injection was $3.10 \pm 0.42 \mathrm{pmol} / 15 \mathrm{~min}(\mathrm{n}=31$. mean \pm S.E.M.) for acetylcholine in $30 \mu l$ of striatal perfusate.

Atropine, scopolamine, and its quaternary compounds, atropine methylbromide and methscopolamine bromide, were tested for their effects on striatal acetylcholine release in the freely moving rats. Atropine increased the level of acetylcholine in striatal perfusates. The high dose of atropine $(5 \mathrm{mg} / \mathrm{kg}$ ) caused a maximal $370 \%$ increase in acetylcholine $1 \mathrm{hr}$ after the injection; then acetylcholine decreased gradually over the following $180 \mathrm{~min}$. A low dose of atropine $(2.5 \mathrm{mg} / \mathrm{kg})$ also elevated striatal acetylcholine release, but it was less effective than the high dose (Fig. 1). The high dose of atropine increased motor activity. While the low dose of atropine 


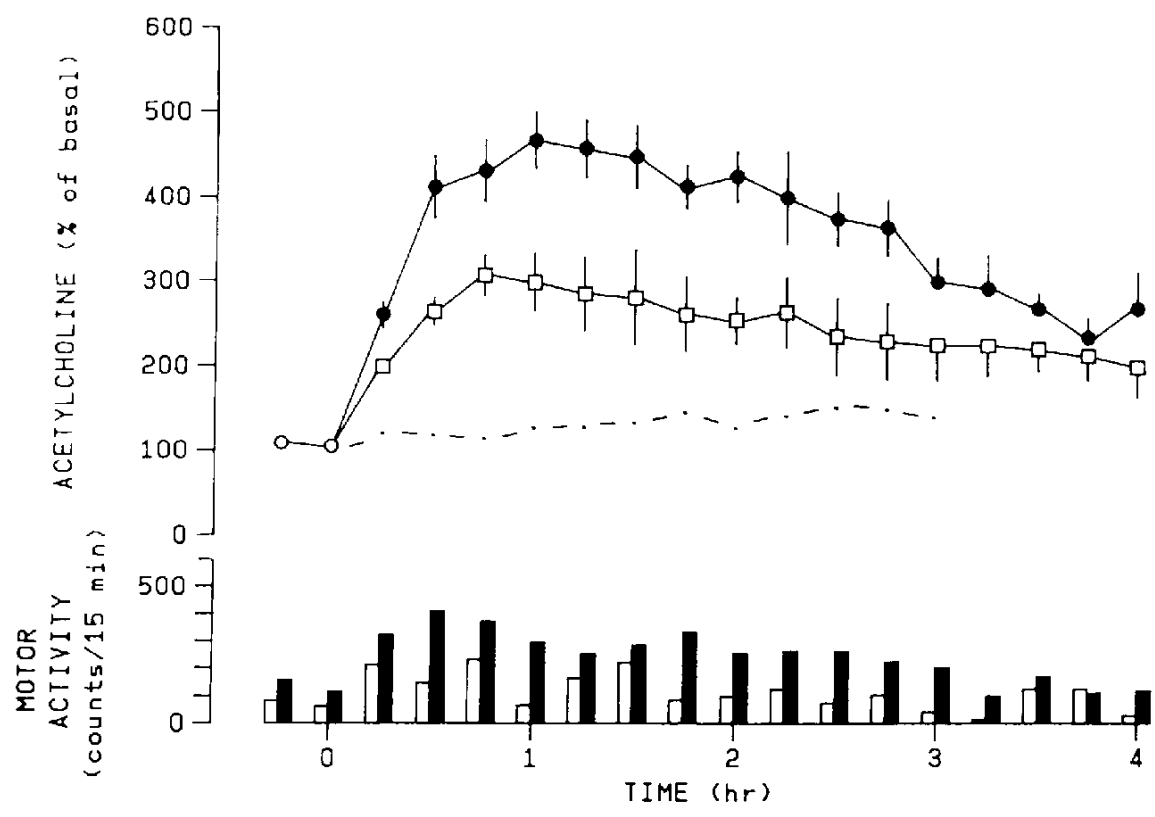

Fig. 1. Exfect of atropine sulfate on striatal acetylcholine release and motor activity in freely moving rats. Acetylcholine in striata! perfusates and spontaneous motor activity were measured for $4 \mathrm{hr}$ after the injection. Acetylcholine levels are expressed as \% (mean $=5 . E . M . n=4$ ) of the mean of three control samples taken immediately before drug administration. Motor activity is the mean count per 15 min period. The doses of atropine: - - - control: $\square-\ldots-\square$ and white column, $2.5 \mathrm{mg} / \mathrm{kg} ; 0-1$ and black column, $5.0 \mathrm{mg} / \mathrm{kg}$.

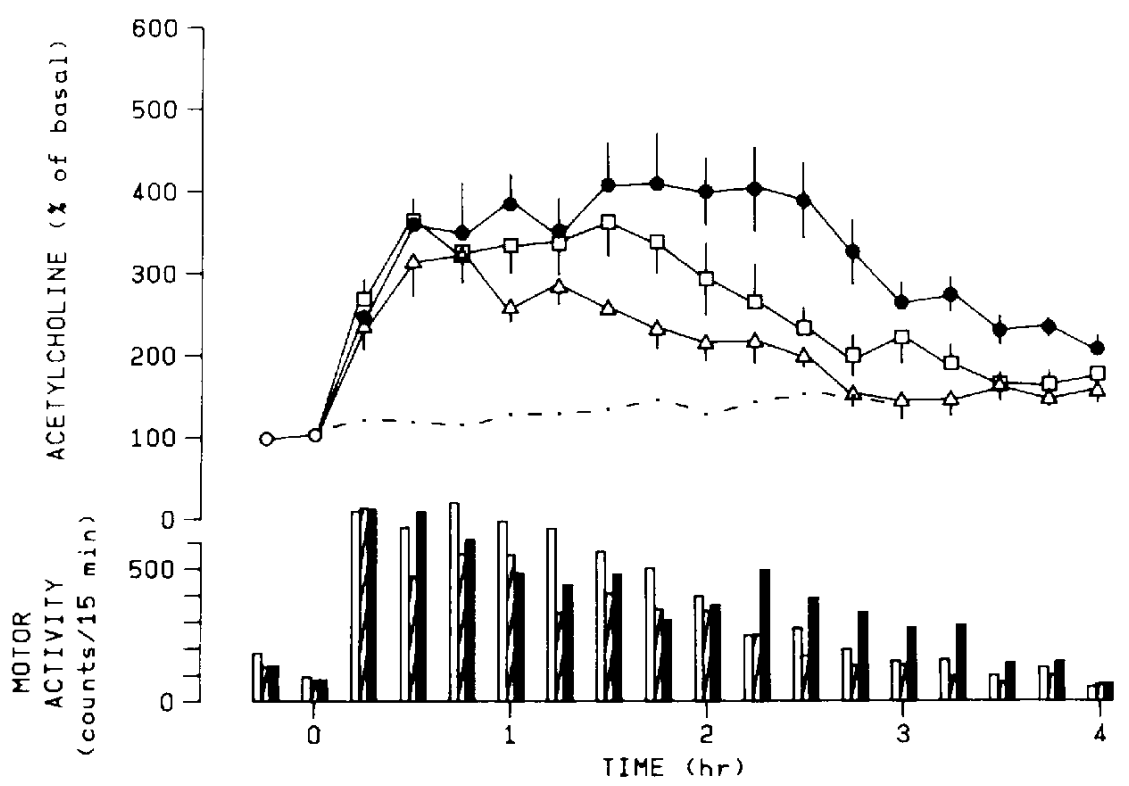

Fig. 2. Effect of scopolamine on striatal acetylcholine release and motor activity in freely moving rats. Acetylcholine levels and motor activity are expressed as described in Fig. 1 . The dose of scopolamine: $-\bullet$. control: $\triangle \longrightarrow \triangle$ and white column, $2.5 \mathrm{mg} / \mathrm{kg} ; \square-\square$ and hatched column, $5.0 \mathrm{mg} / \mathrm{kg}$; -_ and black column, $10.0 \mathrm{mg} / \mathrm{kg}$. 


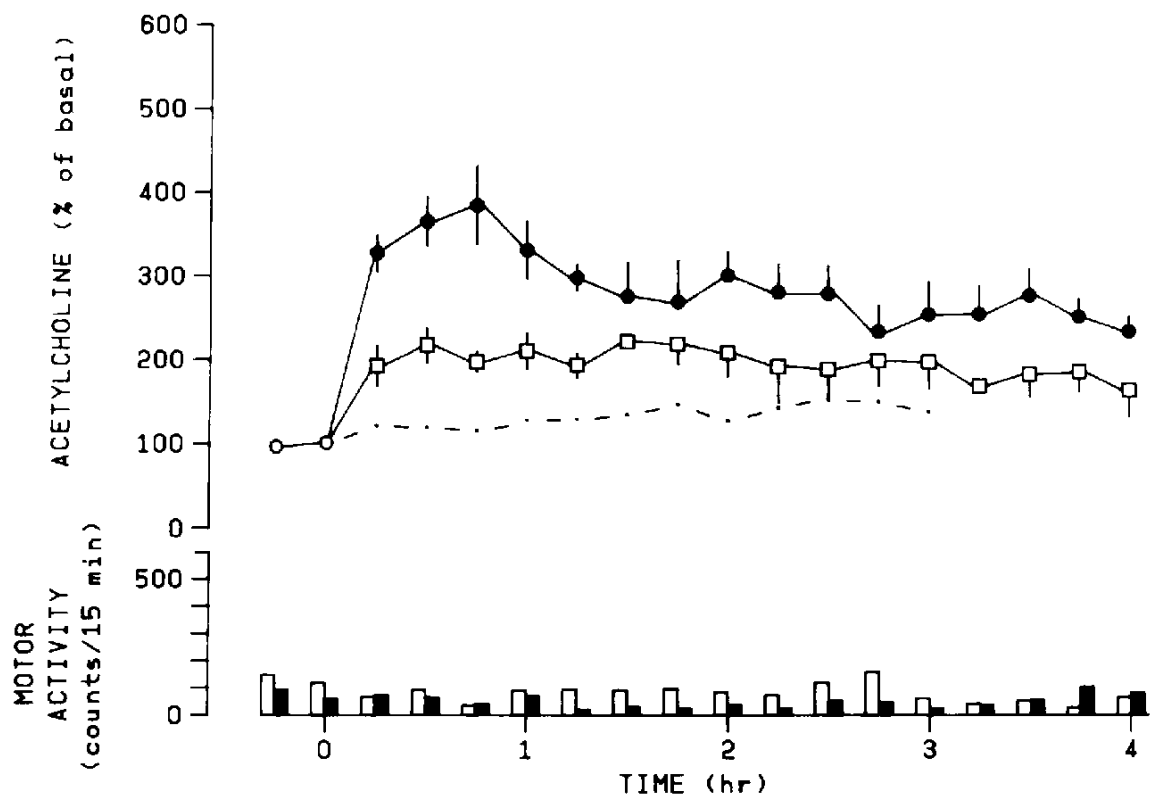

Fig. 3. Effect of atropine methylbromide on striatal acetylcholine release and motor activity in freely moving rats. Acetylcholine levels and motor activity are expressed as described in Fig. 1. The doses of atropine methylbromide: - - - control: $\square-\square$ and white column, $2.5 \mathrm{rg} / \mathrm{kg} ;-\longrightarrow$ and black column, $5.0 \mathrm{mg} / \mathrm{kg}$.

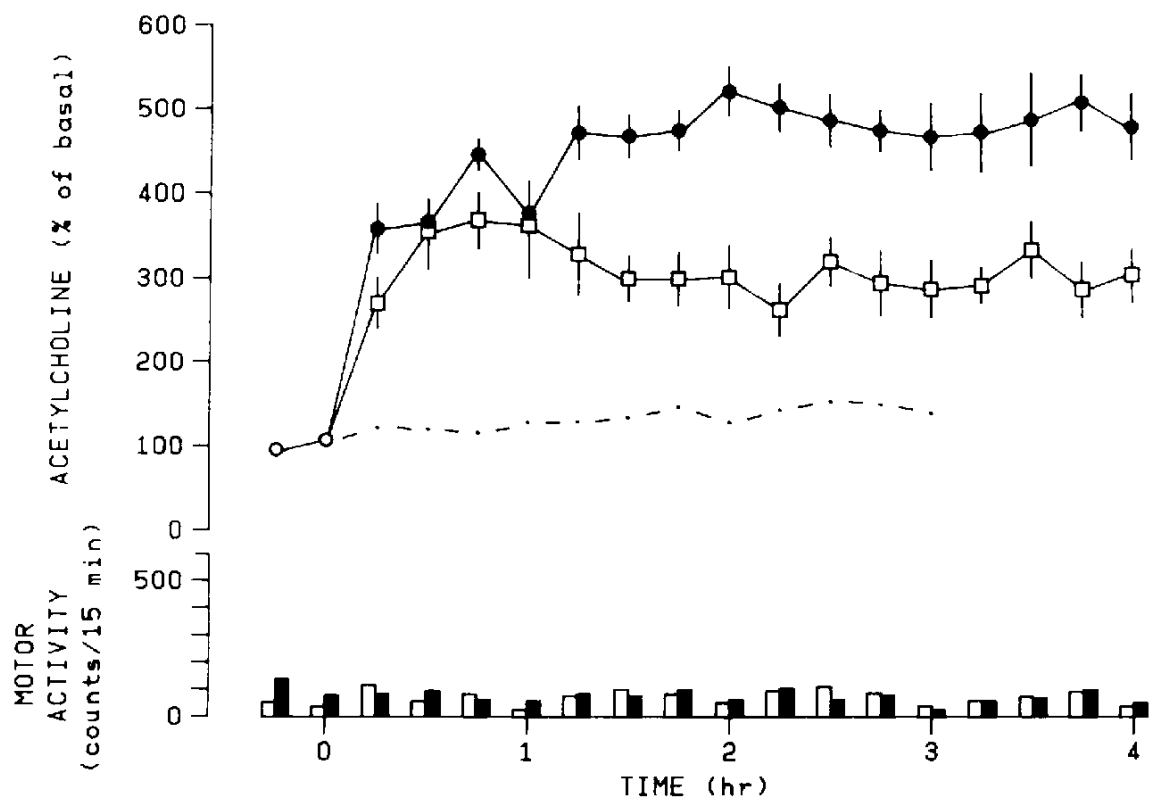

Fig. 4. Effect of methscopolamine bromide on striatal acetylcholine release and motor activity in freely moving rats. Acetylchnline levels and motor activity are expressed as described in Fig. 1. The doses of methscopolamine:-- - control; $\square-\square$ and white column, $5.0 \mathrm{mg} / \mathrm{kg}$ : - - and black column. $10.0 \mathrm{mg} / \mathrm{kg}$. 


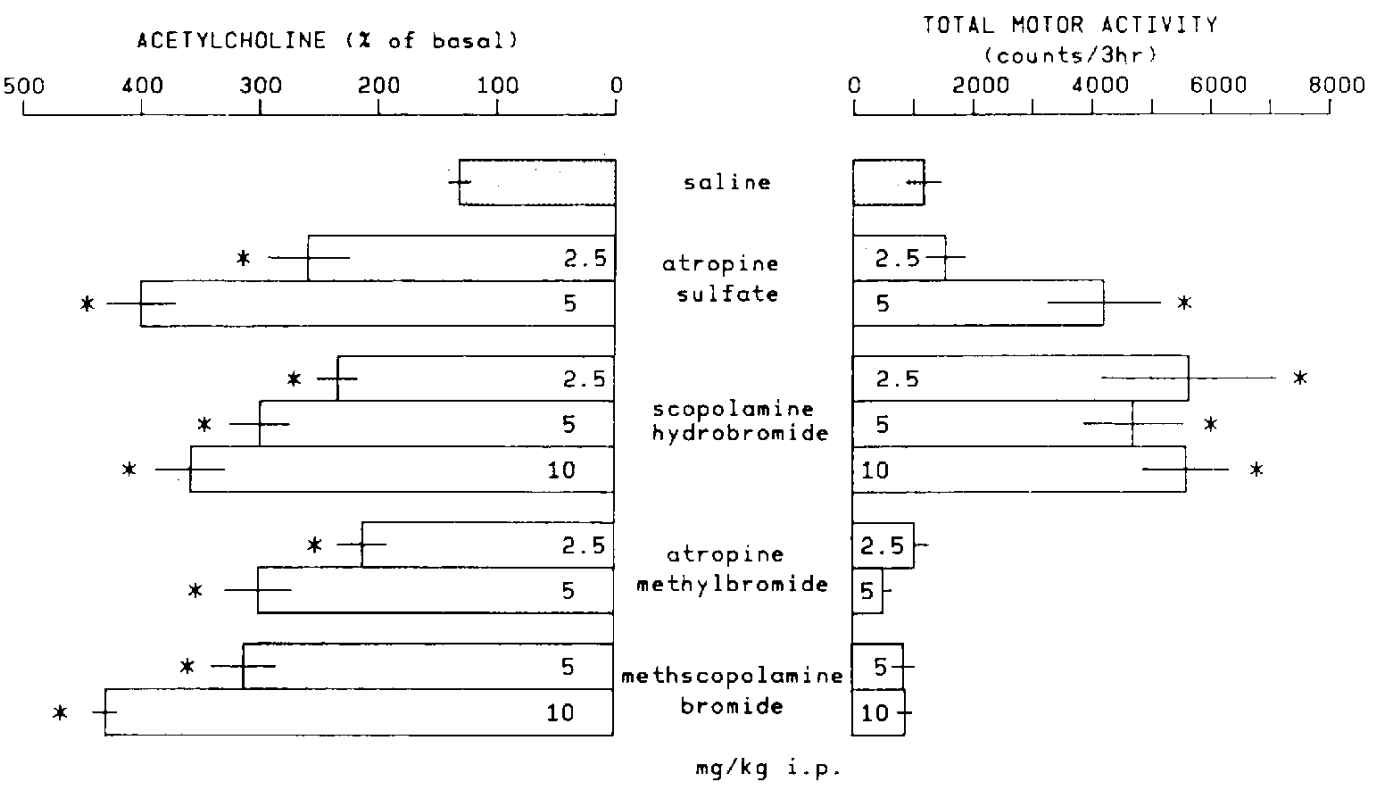

Fig. 5. Summary of the effect of anticholinergic drugs on acetylcholine release and motor activity in freely moving rats. Acetylcholine levels are the accumulated amount recovered in striatal perfusates for $3 \mathrm{hr}$ after the drug administration and are expressed as \% of the total basal amount of acetylcholine recovered for $3 \mathrm{hr}$. Total motor activity is the accumulated counts for $3 \mathrm{hr}$ after the drug administration. The column and bar represent the mean \pm S.E.M. $(n=4-5) . \quad{ }^{*} P<0.01$.

showed no effect on it.

Scopolamine at a dose of $10 \mathrm{mg} / \mathrm{kg}$ caused a marked increase in acetylcholine release (Fig. 2). This increase was $300 \%$ at $90 \mathrm{~min}$ after the injection, and acetylcholine release did not return to baseline for $3 \mathrm{hr}$ after the drug. A lower dose of scopolamine, $5 \mathrm{mg} / \mathrm{kg}$. caused a maximal $350 \%$ increase in acetylcholine release at $30 \mathrm{~min}$; then acetylcholine returned to control levels over the following $2 \mathrm{hr}$ after the injection. The lowest dose of scopolamine $(2.5 \mathrm{mg} / \mathrm{kg})$ also elevated acetylcholine release (a maximal $200 \%$ ), and the release levels returned to the control at 2.5 $\mathrm{hr}$ after the drug. All doses of scopolamine caused a pronounced increase in motor activity.

Atropine methylbromide $(5 \mathrm{mg} / \mathrm{kg}$ ) caused a pronounced rise in acetylcholine release over $4 \mathrm{hr}$ after the injection (Fig. 3). Atropine methylbromide at a dose of $2.5 \mathrm{mg} / \mathrm{kg}$ also elevated striatal acetylcholine release over 2 $\mathrm{hr}$ after the injection. Atropine methylbromide $(2.5$ and $5.0 \mathrm{mg} / \mathrm{kg}$ ) had no effect on spontaneous motor activity.
Methscopolamine bromide ( 5 and $10 \mathrm{mg} /$ $\mathrm{kg}$ ) caused a maximal increase (380 and $430 \%$, respectively) in acetylcholine release $2 \mathrm{hr}$ after the injection, and the release levels did not return to the baseline over $4 \mathrm{hr}$ after the drug (Fig. 4). Methscopolamine (5 and $10 \mathrm{mg} / \mathrm{kg}$ ) had no effect on spontaneous motor activity. The effects of the anticholinergic drugs on acetylcholine release and spontaneous motor activity are summarized in Fig. 5.

After 4 hr-perfusion, striatal acetylcholine content was measured in two regions of the striatum, the vicinity of the tube and distant area from the tube, of saline or scopolamine (2.5 mg/ $/ \mathrm{kg})$ injected animals. There were no significant differences of acetylcholine content between both treatments (Table 1).

\section{Discussion}

The validity of measurement of acetylcholine release from the striatum using an intracerebral dialysis technique in freely moving rats has been shown previously (for review, 16). Our results show that a high dose 
Table 1. Striatal content of acetylcholine ( $\mathrm{nmol} / \mathrm{g}$ ) after the injection of scopolamine $(2.5 \mathrm{mg} / \mathrm{kg}$. i.p.) followed by $4 \mathrm{hr}$ perfusion

\begin{tabular}{cccc}
\hline & $\begin{array}{c}\text { No. of } \\
\text { Rats }\end{array}$ & $\begin{array}{c}\text { The vicinity } \\
\text { of the tube }\end{array}$ & $\begin{array}{c}\text { Distant area } \\
\text { from the tube }\end{array}$ \\
Saline control & 5 & $33.5 \pm 6.6$ & $25.5 \pm 4.9$ \\
Scopolamine & 4 & $46.6 \pm 5.9$ & $30.1 \pm 3.1$ \\
\hline
\end{tabular}

Animals were killed by decapitation after the perfusion experiment, and bilateral striata were excised and separated into two parts, the vicinity of the dialysis tube and distant area from the tube.

of atropine and scopolamine increase striatal acetylcholine release and motor activity, while its quaternary ammonium salts, atropine methylbromide and methscopolamine bromide, increase only acetylcholine release from the striatum. These effects are quite similar to those of atropine and its quaternary compound, methylatropine glycolate, studied in the rat cerebral cortex using the epidural cup technique. A small dose of atropine caused an increase in cortical acetylcholine release and high doses of atropine increased both acetylcholine release and locomotor activity. while methylatropine glycolate caused merely an increase in acetylcholine release from the cortex (10). Taken together, these results suggest that anticholinergic drugs-induced increase in acetylcholine release in the striatum and cerebral cortex is not always associated with the increase in motor activity.

It is thought that central effects of quaternary ammonium compounds are generally lacking. because they do not readily pass the blood brain barrier. On the contrary. Aquilonius et al. (10) showed that the quaternary salt of atropine was permeable to the cerebral cortex not through the blood-brain barrier but through a blood-subarachnoidal spacecortex pathway. This may be the case in the striatum because the head of the caudate nucleus is bordered by the cerebral ventricle. There is a possibility that the blood-brain barrier is regionally damaged by the implantation of a dialysis tube in the striatum, which results in the passing of quaternary compounds through the barrier. However, Ungerstedt (11) has shown evidence that the dialysis tube is functionally within the bloodbrain barrier. Intravenously administered sodium technitate, which was not able to penetrate the barrier. was not found in the dialysate, while $\left[{ }^{3} \mathrm{H}\right]-\mathrm{H}_{2} \mathrm{O}$ that was able to penetrate the barrier entered the dialysate. It is also possible that quaternary salts of anticholinergic drugs are metabolized peripherally, penetrate the blood-brain barrier and act on the striatum, whereas no such active metabolite has been identified in the brain.

It is unclear why quaternary salts of the anticholinergic drugs which cause a significant increase in acetylcholine release in the striatum do not produce motor activation. although the following causes may be responsible. First, different sites of action are involved. In cats, methylatropine was more potent in eliciting acetylcholine release than electroencephalographic changes, and it was suggested that sites responsible for the acetylcholine release were more accessible from the blood stream than sites from which electroencephalographic changes were elicited (17). Second, different action mechanisms at the receptor level are involved. The quaternary ammonium compounds usually have greater potency at nicotinic receptors than at muscarinic receptors, as compared with the parent anticholinergic drugs (18).

The present study has shown that high doses of four anticholinergic drugs cause an increase in striatal acetylcholine release over $3 \mathrm{hr}$. These drug-induced increases in acetylcholine release are considered to be due to an inhibition of the muscarinic negative control of the acetylcholine release from striatal cholinergic terminals (19). A presynaptic control of acetylcholine release by muscarinic autoreceptors has been confirmed by a blockade of the inhibitory effect with atropine in slices of the cerebral cortex $(20,21)$, a structure which receives its cholinergic innervation mainly from the nucleus basalis of Meynert (22). The existence of such regulation in the striatum is probable because 
atropine also enhances acetylcholine release both in vitro and in vivo $(20-24)$. In the striatum, however, we cannot exclude a possibility that the regulation is mediated through a negative feedback loop including other interneurons, since most of the cholinergic neurons are intrinsic (25).

Our results that striatal acetylcholine content shows a tendency to increase after scopolamine injection followed by $4 \mathrm{hr}$ perfusion indicate that acetylcholine release induced by the anticholinergic drug does not result in the depletion of acetylcholine stores in the cholinergic nerve endings.

In conclusion, the present study shows that anticholinergic drugs produce an increase in striatal acetylcholine release which does not always result in the increase in motor activity.

Acknowledgment: This work was supported by a Grant-in-Aid for Scientific Research (No. 52570979) from the Ministry of Education. Science and Culture. Japan.

\section{References}

1 Arnfred, T. and Randrup, A.: Cholinergic mechanisms in brain inhibiting amphetamine-induced stereotyped behavior. Acta Pharmacol. Toxicol. 26, 384-394 (1968)

2 Scheel-Krüger, J.: Central effects of anticholinergic drugs measured by the apomorphine gnawing test in mice. Acta Pharmacol. Toxicol. 28. 1-6 (1970)

3 Pycock, C., Milson, J., Tarsy, D. and Marsden, C.D.: The effect of manipulation of cholinergic mechanisms on turning behavior in mice with unilateral destruction of the nigro-neostriatal dopaminergic system. Neuropharmacology 17. 175-183 (1978)

4 Malatray, J. and Simon, P.: Comparison de quelques effets centraux chez l'animal de l'atropine, de la scopolamine et de leurs dérivés ammonium quternaire. Therapie 27, 153-166 (1972)

5 Kuribara, $\mathrm{H}$. and Tadokoro, S.: Characteristics of effects of repeated scopolamine administration on ambulatory activity in mice and methamphetamine sensitivity in the scopolamine-experienced mice: Comparison among 6 strains. Japan. J. Pharmacol. 45, 551-558 (1987)

6 Watanabe, H., Watanabe, K. and Hagino, K.: The involvement of catecholamine in scopolamine-induced locomotor activation and rotational behavior in mice. Japan. J. Pharmacol. 28 , 465-472 (1978)
7 Barbeau, A.: The pathogenesis of Parkinson's disease: a new hypothesis. Can. Med. Assoc. J. 87, 802-807 (1962)

8 McGeer, P.L., Boulding, J.E., Gibson, W.C. and Foulkes, R.G.: Drug-induced extrapyramidal reactions. J. Am. Med. Assoc. 177, 665-670 (1961)

9 Frances, H. and Jacobs, J.: Comparison des effets de substances cholinergiques et anticholinergiques sur les taux cérébraux d'acetylcholine et sur la motilité chez la souris. Psychopharmacology (Berlin) 21, 338 (1971)

10 Aquilonius, A.-M., Lundholm, B. and Windbladh, B.: Effects of some anticholinergic drugs on cortical acetylcholine release and motor activity in rats. Eur. J. Pharmacol. 20, 224-230 (1972)

11 Ungerstedt, U.: Measurement of neurotransmitter release by intracranial dialysis. In Measurement of Neurotransmitter Release In Vivo. Edited by Marsden, C.A., p. 81-105, John Wiley \& Sons, New York (1984)

12 Imperato, A. and DiChiara, G.: Dopamine release and metabolism in awake rats after systemic neuroleptics as studied by trans-striatal dialysis. J. Neurosci. 5, 297-306 (1985)

13 Pellegrino, K.J. and Cushman, A.J.: A Stereotaxic Atlas of the Rat Brain. Appleton Century Crofts. New York (1967)

14 Potter, P.E., Meek, J.L. and Neff, N.H.: Acetylcholine and choline in neuronal tissue measured by HPLC with electrochemical detection. J. Neurochem. 41, 188-194 (1983)

15 Fujimori, K. and Yamamoto, K.: Determination of acetylcholine and choline in perchlorate extracts of brain tissue using liquid chromatographyelectrochemistry with an immobilized-enzyme reactor. J. Chromatogr. 414, 167-173 (1987)

16 Westerink, B.H.C., Damsma, G., Rollema, H., De Vries, J.B. and Horn, A.S.: Scope and limitations of in vivo brain dialysis: A comparison of its application to various neurotransmitter systems. Life Sci. 41, 1763-1776 (1987)

17 Szerb, J.: The effect of tertially and quaternary atropine on cortical acetylcholine output and on the electroencephalogram in cats. Can. J. Physiol. Pharmacol. 42, 303-314 (1964)

18 Innes, I.R. and Nickerson, M.: Atropine, scopolamine, and related antimuscarinic drugs. In The Pharmacological Basis of Therapeutics, 5th Edition, Edited by Goodman, L.S. and Gilman, A. p. 514-532, Macmillan. New York (1975)

19 Lefresne, P., Rospars, J.P., BeauJouan, J.C., Westfall, T.C. and Glowinski, J.: Effects of acetylcholine and atropine on the release of ${ }^{14} \mathrm{C}$ acetylcholine formed from $U-{ }^{4} \mathrm{C}$-glucose in rat 
brain cortical and striatal prisms. Naunyn Schmiedebergs Arch. Pharmacol. 303, 279-285 (1978)

20 Hadházy, P, and Szerb, J.C.: The effect of cholinergic drugs on ${ }^{3} \mathrm{H}$-acetylcholine release from slices of rat hippocampus, striatum and cortex. Brain Res. 123, 311-322 (1977)

21 Rospars, J.P., Lefresne, P., Beaujouan, J.C. and Glowinski, J.: Effect of external $A C h$ and of atropine on ${ }^{14} \mathrm{C}$-ACh synthesis and release in rat cortical slices. Naunyn Schmiedebergs Arch. Pharmacol. 300, 153-161 (1977)

22 Lehmann, J.S., Nagy, J.I., Atmadja, S. and Fibiger, H.C.: The nucleus basalis magnocellularis: the origin of a cholinergic projection to the neocortex of the rat. Neuroscience $5,1161-$
$1174(1980)$

23 Jones, B.E., Guyenet, P., Chéramy, A., Gauchy, C. and Glowinski, J.: The in vivo release of acetylcholine from cat caudate nucleus after pharmacological and surgical manipulations of dopaminergic nigrostriatal neurons. Brain Res. 64, 355-369 (1973)

24 Ajima, A. and Kato, T.: Brain dialysis: detection of acetylcholine in the striatum of unrestrained and unanesthetized rats. Neurosci. Lett. 81, 129 132 (1987)

25 McGeer, P.L., McGeer, E.G., Fibiger, H.C. and Wickson, $V$ : Neostriatal choline acetylase and cholinesterase following selective brain lesions. Brain Res. 35, 308-314 (1971) 